\title{
PRotagonismo PoÉtico da MUlHer idosa EM DONA (2018), de Luciene Carvalho
}

\author{
POETIC PROTAGONISM OF THE ELDERLY WOMAN IN DONA (2018), BY \\ LUCIENE CARVALHO
}

DOI: $10.23926 /$ RPD.2526-2149.2020.v5.n2.p754-781.id730

\section{Maria Cleunice Fantinati da Silva \\ Doutoranda em Estudos \\ Literários (UNEMAT) \\ Professora no IFMT - \\ campus avançado Tangará da \\ Serra (IFMT) \\ maria.silva@tga.ifmt.edu.br}

\section{Elisabeth Battista}

Pós-doutorado Sênior pela

Universidade de Aveiro

(UA)

Doutorado e Mestrado em

Letras (USP)

Professora do Programa de

Pós-Graduação em Estudos

Literários (UNEMAT)

bethyunemat@gmail.com
Resumo: A temática do envelhecimento ganhou relevância no contexto atual em que, mundialmente, tem-se registrado o aumento acelerado da população acima dos 60 anos. A literatura, por abranger diversas temáticas e conduzir a inúmeras possibilidades de leituras, tornou-se um rico repertório de conhecimento. Neste estudo, analisou-se dois poemas de Dona, (2018), de Luciene Carvalho, à luz da crítica literária dos estudos de autoria da mulher. Intentou-se desvendar como se articulam os poemas com questões relacionadas à idade da mulher na sociedade brasileira. A pesquisa bibliográfica se pautou na enunciação da elaboração estética a partir da subjetividade feminina buscando legitimar aspectos ligados ao envelhecimento e, a carga pejorativa que sobrepõe à imagem da mulher idosa. Os poemas seguem o percurso da vida e o protagonismo poético da mulher na maturidade sinaliza que a vida só pode ser compreendida olhando-se para o passado e, nesta direção, só poderá ser bem vivida olhando-se para o porvir.

Palavras-chave: Luciene Carvalho. Poesia Feminina. Envelhecimento da Mulher.

\begin{abstract}
The theme of aging gets relevance in the current context in which, worldwide, there has been an accelerated increase in the population over 60 years. Literature, as it encompasses several themes and leads to innumerable reading possibilities, becomes a rich repertoire of knowledge. In this study we analyzed two poems by Dona, (2018), by Luciene Carvalho, the analysis has been based on of the literary criticism of studies on women's authorship. We attempted to discover how the poems are articulated with issues related to the age of women in Brazilian society. The bibliographic research is based on the enunciation of aesthetic elaboration based on female subjectivity, seeking to legitimize aspects related to aging and the pejorative burden that overlaps the image of elderly women. The poems follow the path of life and the poetic role of women in maturity indicates that life can only be understood by looking at the past and, in this direction, it might only be lived well by looking at the future.
\end{abstract}

Keywords: Luciene Carvalho. Feminine Poetry. Aging of Women. 


\section{INTRODUÇÃO}

O estudo propôs analisar dois poemas da coletânea poética intitulada Dona (2018), de Luciene Carvalho, considerando o fato de que ainda os livros escritos por mulheres, em sua grande maioria, são invisíveis nos meios literários, eles existem e, por sua qualidade e expressão literária justificam participar do cânone dito oficial, na medida em que, até então, lhes reserva uma parcela muito inferior a dos homens escritores.

Investigou-se questões contemporâneas como o envelhecimento humano e o discurso poético rememorativo referente ao tempo e espaço. $\mathrm{O}$ eu poético lança aos leitores questionamentos referentes ao envelhecimento feminino. Na tentativa de resposta promoveuse uma discussão teórica sobre conceitos de envelhecimento, de discurso patriarcal, de memória, de paradigmas relacionados ao envelhecimento feminino. Tratou-se, portanto, de uma pesquisa bibliográfica que buscou investigar, através do discurso poético, as imagens sociais predominantes que constituem em diferentes intensidades, a concepção do que é ser idoso. Também se tencionou verificar as demais temáticas abordadas na poesia de Luciene Carvalho, como por exemplo: as lembranças relacionadas ao tempo e ao espaço, à afirmação da identidade e ao tema pouco discutido, inerente à condição da mulher na medida em que esta atinge a fase da vida na qual passa a ser tratada por: "Senhora".

O passar dos anos propiciou a transfiguração do conceito de velhice, se antes o idoso era sinônimo de sabedoria, força e referência; a contemporaneidade ocasionou o fenômeno da gerontofobia, ou seja, o medo de envelhecer. Dado que, ser velho assumiu novos estigmas no decorrer dos anos, como o estigma da lentidão. Contudo, considerando que o discurso patriarcal ainda está intrínseco às sociedades, percebeu-se que a desigualdade de gênero se torna resultado até mesmo nas questões sobre o envelhecimento.

O envelhecimento tem se tornado cada vez mais representativo no Brasil e as mulheres são a maioria expressiva nesse grupo. De acordo com o IBGE, Instituto Brasileiro de Geografia e Estatística (2018) já são 30,2 milhões de idosos, 4,8 milhões a mais do que em 2012. Isso representa um aumento de $18 \%$ na quantidade de pessoas acima dos 60 anos. Além disso, cerca de 56\% das pessoas com mais de 60 anos (16,9 milhões) são mulheres. Posto em parênteses as informações referentes ao perfil demográfico do Brasil no que consiste ao envelhecimento, abordou-se a velhice sob a ótica da ética humanizadora na poesia de Luciene Carvalho.

Esta temática, sustentou o estudo para a compreensão da linguagem contemporânea, utilizada para falar do cotidiano, pois segundo Valderez (2018), a poeta ironiza e brinca com signos/conceitos que funcionam como marcas identitárias da velhice. Na perspectiva da autora 
citada, em Luciene Carvalho a linguagem poética é habitada por múltiplas vozes e afetos, tem sonoridades, expressa sabores e odores, variações climáticas e percorre espaços e tempos diversos, desencadeando outras possibilidades.

Quanto ao referencial teórico, no que tange sobre a escrita feminina, gênero e patriarcado procurou-se articular a escrita poética de Luciene Carvalho PAZ (2003); e temática sobre a velhice, foi abordada a partir de BEAUVOIR (2018); PACHÁ (2018) e pesquisas atuais que contemplem esse assunto.

\section{A MULHER NA SOCIEDADE BRASILEIRA E OS PERCALÇOS PARA A MULHER ESCRITORA}

Ao lançar o olhar para a concepção da sociedade do final do século XIX e, primeiras décadas do século XX, percebeu-se uma certa construção social da imagem acerca do sexo feminino associada aos atributos de pureza, doçura, moralidade cristã, maternidade, generosidade, espiritualidade e patriotismo, entre outros, que colocavam as mulheres como responsáveis por toda beleza e bondade que deveriam impregnar a vida social.

A educação feminina, segundo os positivistas, o trabalho intelectual iria exauri-las, pois, a finalidade da educação para essas mulheres era prepará-las para atuarem no espaço doméstico, gerar prole numerosa e se dedicarem a cuidar do marido e dos filhos. E não se considerava a possibilidade de as mulheres exercerem qualquer atividade profissional.

Os colonizadores portugueses trouxeram para o Brasil uma provinciana visão de mundo, expressivamente calcada no pensamento medieval, e uma gama de pensamentos cristalizados que não condiziam com as transformações científicas do restante do Velho Mundo. Segundo Serra (2017), antes de tornarem-se escritoras, as mulheres tiveram de assimilar a escrita e nesse processo de construção da linguagem, submeter-se, incorporar-se a uma linguagem restrita e elaborada segundo padrões de uma elite branca e boa parte das vezes de origem europeia, [...]. A demarcação do espaço masculino estabeleceu a inferioridade de mulher e dificultando o seu acesso a outros espaços que não fosse o lar, pois como se sabe, via de regra, apenas ao homem era facultado o acesso ao saber escolarizado.

Neste sentido, a mulher encontrou um persistente empecilho para seu reconhecimento, enquanto intelectual, uma vez que a ela foi negado durante muito tempo o direito à educação. Nesta incessante busca pelo reconhecimento

[...] as mulheres fundaram e dirigiram jornais e revistas femininos. Nestes eram comuns temas ligados à literatura, ao teatro, às artes de forma geral, à moda, à mulher, às condições sociais em que viviam, às discussões sobre os espaços por elas almejados. Data de 1852 o primeiro periódico feminino brasileiro feito por mulheres, 
o Jornal das Senhoras, editado no Rio de Janeiro. [...] (DUARTE; PAIVA, p. 16, 2009).

A mulher conseguiu chegar à imprensa, mas dificuldades para que reconhecessem a sua capacidade e o seu direito de ser escritora continuaram existindo. Ela não conseguiu se desvincular da intensa carga de atribuições ao longo dos anos, impostos pelo cotidiano destinadas à mulher. Os rotineiros e exaustivos afazeres domésticos eram empecilhos para os novos interesses relativos à participação na vida intelectual feminina.

A crescente urbanização e a rápida evolução industrial, nos anos trinta do século XX, contribuíram para ampliar a visão da mulher brasileira para além dos limites domésticos. $\mathrm{O}$ rádio foi um dos instrumentos representativos que adentra os lares das famílias brasileiras informando sobre as mudanças da vida moderna. Segundo Almeida;

\section{Após o término do regime ditatorial que se implantou no Brasil com o golpe de Estado em 1937, a retomada dos ideais democráticos coincidiu com o final da Segunda Guerra Mundial e contribuiu para mudanças nas representações culturais acerca da educação feminina e do papel das mulheres na nova sociedade que emergia. (ALMEIDA, p. 27, 1998).}

Somente na década de 1960, com a lenta e gradativa ruptura com o sistema patriarcal, iniciando, assim, o movimento de libertação da mulher no Brasil. As mudanças foram perceptíveis na década de 1970 e, em 1977, foi aprovada a Lei do Divórcio (Lei nº 6.515,77), pois mulheres da segunda metade do século XX eram diferentes das pioneiras dos anos iniciais. Considerando que a educação, no Brasil século XIX, era limitada para as mulheres. As primeiras manifestações de protesto contra a subordinação das mulheres iniciaram-se no Rio de Janeiro, por volta de 1872 .

De acordo com apreciações de Hahner (2003), o sistema escolar brasileiro exprimia o consenso social sobre o papel da mulher. Ensinava-se a ela o que fosse considerado necessário para viver em sociedade. As poucas escolas neste século enfatizavam atividades complementares aos papéis femininos de esposa e mãe. As diferenças entre a educação reservada para homens e a destinada às mulheres reforçavam a ideia de mundos masculino e feminino distintos.

Atualmente, as mulheres podem determinar o número de filhos que querem ter, e isto significa que elas têm possibilidades de tomar decisões. De acordo com Rago (2004), esta tomada de decisão, a independência econômica, a liberdade para agir, dissocia sua definição de gênero da ideia de maternidade, afinal, ser mulher, no século XXI, deixou de implicar necessariamente gravidez e parto, o que traduz uma enorme ruptura com a ideologia da domesticidade. 
A liberdade de agir possibilitou às mulheres a oportunidade de inovação e, constantemente elas vêm se firmando nos espaços que ocupam. Assim, evidenciam-se as afirmações de Rago (2004), visto que são mais independentes não só economicamente,

[...] mas também emocional e sexualmente, as mulheres do século XXI, deixam de acreditar que deveriam dedicar-se exclusivamente a promover o crescimento profissional do parceiro/marido ou ainda contentar-se em satisfazê-lo sexualmente, a despeito do seu próprio desejo. (RAGO, 2004, p.37).

As mulheres se tornaram, neste século, por assim dizer, "artífices", donas de seus próprios desejos, destacando-se por seu significativo e notório desempenho profissional e intelectual. Assumiram a condição de "chefe de família", e a dupla jornada de trabalho as impulsionaram a ser múltiplas.

\subsection{A ESCRITA AFRO-FEMININA NO BRASIL}

Os percalços enfrentados pela mulher brasileira para conquistar o direito da escrita foram inúmeros, entretanto, ao pensar sobre a escrita afro-feminina é possível supor que as dificuldades foram bem maiores. A escravatura tingiu as páginas de nossa história de sangue e desenhou horrores. Para a mulher negra a escrita se transformou num ato de resistência.

Ferreira e Migliozzi (2016) comentam que é provável que a literatura afro- feminina teve início no ano de 1859, com a publicação do romance Úrsula, de Maria Firmina dos Reis. O romance discorre sobre questões femininas e também sobre a mulher e faz uma forte crítica ao sistema patriarcal e também uma denúncia do tráfico negreiro.

O simples fato de ser mulher na cultura latina americana, sobretudo, sociedade brasileira implica em desafios, mas quando se é negra, a desvalorização é explícita e os reveses são maiores. O olhar externo lançado sobre a literatura produzida pela mulher negra, ainda está carregado de estigmas e preconceitos que são reflexos do processo de colonização e das imposições da cultura patriarcal que insiste na desvalorização da escrita da mulher.

Neste sentido, recorreu-se à entrevista de Conceição Evaristo, postada no Correio Braziliense. Segundo Maciel (2018), a escritora relata que ao sair de um evento se esbarrou em uma senhora com formação de arquivista e foi reconhecida, provavelmente de algum programa de entrevistas. E, a mulher lhe perguntou o que ela fazia. Conceição respondeu que era escritora e a mulher imediatamente perguntou se a romancista era autora de livros de receitas. "E não estamos falando de uma pessoa sem leitura! Essa até deu um salto adiante: mulher negra até pode escrever, mas tem que ser um livro de receita. Então, escrever e publicar são atos de 
rebeldia que nos colocam em outro lugar, contrariando o imaginário que a sociedade brasileira tem sobre nós".

Urge a necessidade de cada vez mais buscar meios para que a literatura considerada, como "interior" e /ou inferior, escrita por mulher negra e produzida fora dos grandes centros tenha o devido reconhecimento.

\subsection{A ESCRITORA MATO GROSSENSE - DONA DE SUA POESIA}

Luciene Carvalho é escritora e poeta brasileira, natural de Corumbá (MS) e mudou-se para Cuiabá (MT) e viveu desde a infância no bairro do Porto. A escritora tornou-se a primeira mulher negra a ingressar na Academia Mato-Grossense de Letras, ocupando a cadeira de $\mathrm{n}^{\circ} 31$. Além de produzir literatura em Mato Grosso, também é declamadora, produz performances em shows poéticos ao vivo, nos quais, une figurino, efeitos cênicos e trilhas musicais para oferecer sua poesia viva e colocá-la a serviço de emoção e da plateia.

O primeiro livro de Luciene, publicado pela FLAMP em 1994, trata-se de uma coletânea intitulada "Devaneios Poéticos". O segundo livro da escritora é "Teia" publicado em, 2000, seguido da publicação de "Caderno de caligrafia", no ano de 2003. A primeira edição de "Porto" aconteceu em 2005, com imagens fotográficas de Romulo Fraga. "Cururu e Siriri do Rio abaixo", em 2007; também neste mesmo ano a trilogia "Conta-Gotas", "Sumo de Lascívia" e "Aquelarre ou livro de Madalena". Em 2009, lança "Insânia” e, em 2012 "Ladra de Flores". Por último temos "Dona”, lançado em 2018.

Dona (2018) é o $11^{\circ}$ livro, pois Luciene publicou a cartilha "Para onde os caminhos levam", em 2012, com a temática dependência química atendendo ao pedido da Secretaria de Justiça do Estado de Mato Grosso. De acordo com sua entrevista ao Olhar Cênico a poeta considera como livro, pois também é escrita em versos.

A temática do livro Dona (2018) é o tempo, a cronologia (Idade), a experiência de vida, o tempo anterior (passado) e a maturação. Também faz alusão à resiliência. A poética de Dona (2018) se concretiza com a maturidade da mulher, da escritora Luciene de Carvalho, porque;

[...] A poesia não nos dá vida eterna, mas nos faz vislumbrar aquilo que chama Nietzsche "a vivacidade incomparável da vida". A experiência poética é um abrir as fontes do ser. Um instante e jamais. Um instante é para sempre. Instante no que somos e o que fomos e seremos. Nascer e morrer: um instante. Nesse instante somos vida e morte, isto e aquilo. (PAZ, 2003, p.155).

A produção poética de Luciene Carvalho faz pacto com a vida. Em Dona (2018) sua poética assume o corpo fêmeo, "E a mulher sangra, / porque esse é o seu grito/ a cada lunação. 
/ A mulher sangra, /pois seu fígado é útero.” (CARVALHO, 2018, p.37). Essa relação intensa com a vida que a poesia Lucienica busca nos remete a Bosi (1997) ou seja, ao "mundo-da-vida".

Após a morte do pai, a escritora e poeta Luciene Carvalho mudou-se para Cuiabá (MT), com sua mãe, e viveu sua infância no bairro do Porto. A criatividade da escritora transcende o espaço físico e sua plenitude lírica habita na alma feminina. A escritora tornou-se a primeira mulher negra a ingressar na Academia Mato-Grossense de Letras, ocupando a cadeira de $\mathrm{n}^{\mathbf{o}} 31$.

A temática do livro Dona (2018), como já mencionado, é referente ao tempo, a cronologia (Idade) e a experiência de vida. A idade da mulher madura é corporificada na poesia da escritora, evidenciando assim,

[...] A revelação poética descobre a condição humana - a solidão de ser jogado - e nos convida a realiza-la plenamente ao exprimi-la através da imagem que comporta a dualidade e contraditório, a representação e a realidade. A revelação poética resulta da inspiração que é uma manifestação da alteridade do homem, pois ela surge concretamente pela palavra que é o meio de que o homem dispõe para fazer-se outro. [...]. (PAZ, 1996, p.271).

O livro está dividido em cinco partes. A parte que inicia a exposição das poesias em Dona (2018), intitula-se Espelho. Nesta parte, as poesias expressam a descoberta do eu poético enquanto mulher e o auto reconhecimento. $\mathrm{O}$ eu poético apresenta a descoberta de si como mulher com atributos e defeitos.

A segunda parte, intitulada por Caixa de Pandora - o eu-poético revela a mulher que se encontra em dificuldades diante das mazelas do dia a dia. Apresenta a mulher comprometida com a família. A descoberta da mulher de 50 anos.

Na terceira parte: Chave - estão os poemas do momento da virada. Liga o ponto da mudança. E na quarta parte - Semáforo- o Eu lírico precisa seguir em frente, não pode parar, não deve permanecer em compasso de espera. Nota-se a aparente necessidade de cortar os vínculos (cortar o cordão umbilical), da mulher que toma posse e segue a própria vida, casar e descasar, ter ou não ter filhos, buscar pela realizado profissional, etc.

E, por fim, a quinta parte - Mandala - a poética está relacionada à espiritualidade, o equilíbrio diante da crise. Existem cenas, nesse quinto momento da coletânea, em que o "eu poético" vivencia o luto com a inevitável perda da mãe. O tema da morte será também vivenciado pela autora uma vez que esta vem a perder a sua mãe durante a escrita da obra. E, por esta razão, a sua poesia, em certa medida apresenta fortes indícios autobiográficos e memorialísticos, pois frequentemente retoma a figura materna que já partiu deste mundo, fato que a autora, em tom confessional, declara que a deixou desolada. 


\section{Metodologia}

Este estudo é de cunho bibliográfico que, segundo Gil (2002), desenvolveu-se ao longo de uma série de etapas. Primeiramente foram levantados os referenciais bibliográficos sobre análise da poesia, dentre eles, PAZ (2003) e BOSI (1977). Quanto a temática da velhice buscouse por BEAUVOIR (2018); PACHÁ (2018) e outros que se foram necessários, pois forneceram os dados essenciais para a elaboração do trabalho.

Para a sustentação da temática expressa, nos poemas analisados, recorreu-se à poetas consagradas pelo cânone literário, como por exemplo, Cecília Meireles. No poema "Retrato" o eu- poético fica consternado diante da percepção da mocidade perdida. Também, se encontrou suporte relacionados a questões do inconformismo poético quanto ao envelhecimento, nos versos do poema "Páscoa" de Adélia Prado. E, no soneto "Pior Velhice", de Florbela Espanca, que logo no primeiro verso, o eu- poemático reconhece a profunda tristeza de ser uma mulher idosa: "Sou velha e triste"

Após o levantamento do recorte teórico, realizou-se as leituras críticas/analíticas objetivando a intelecção do texto, pois segundo Durão (2015), o cerne da pesquisa em literatura acontece em torno da interpretação. Todas as leituras realizadas foram registradas através de anotações e fichamentos a fim de facilitar o processo de consulta às teorias, quando necessário.

Na sequência, convergiu-se à análise e interpretação dos textos poéticos "A Busca da Resiliência" e “A Invisíveis"; selecionados no livro de poesia Dona (2018) de Luciene de Carvalho.

\section{ReSultados E Discussões}

Será apresentada a análise de dois poemas da primeira parte, intitulada - Espelho - da obra poética de Luciene Carvalho Dona (2018). Os poemas analisados são “A Busca da Resiliência" e "As Invisíveis". Os poemas apresentam o momento de transição da mulher que inesperadamente é surpreendida pelo tratamento "Senhora" que provoca no eu poético, certo estranhamento.

\subsection{DONA E OS REFLEXOS DAS FASES DA VIDA}

Os múltiplos universos femininos se adensam nos cinco capítulos de Dona (2018) de Luciene Carvalho. No primeiro capítulo, intitulado por - Espelho - a mulher passa a se enxergar de forma real, no seu cotidiano. Os versos do poema "Retrato" de Cecilia Meireles refletem a tristeza diante da percepção do eu lírico ao observar o próprio retrato. Lança seu olhar para o rosto, visto que segundo Farra (2005), “Eu não tinha este rosto de hoje”, é a prospecção da 
própria imagem que leva à constatação de profundas mudanças perpetradas em sua pessoa e que sequer foram pressentidas pela poetisa.

Na primeira poesia, deste capítulo, “A Busca da Resiliência”, (p. 17- 18) Luciene Carvalho poetisa um acontecimento corriqueiro que, entretanto, surte um efeito impactante para a auto estima na vida da mulher. O fato decorre em público no ato de fazer compras. Logo no primeiro verso, ao ser indagada pela voz do outro: “A senhora vai levar quantos?”, a frase soa como um constrangimento para a mulher. $\mathrm{O}$ eu poético revela que a mulher, de súbito, se sente como se estivesse, de repente, desnuda. A reiterada expressão "senhora" ressoa como uma revelação pública de algo que sempre cuidou para ocultar: a idade. Ali, com o espírito em desalinho, percebe no seu cotidiano de que o tempo cronológico está passando; visto nos versos que seguem;

[...]

Específico,

recolho o produto embalado

e fico ainda como quem aprende

a levar ao lado,

quando vai embora,

o novo chamamento

de senhora!

Não nego o estranhamento

quando no momento

a palavra ainda ressoa...

[...]

SENHORA!

Como souberam?

Quem contou para eles

a minha idade?

Será que é um complô

Que armaram na cidade?

Deve ser isso!

Porém,

no fundo do meu ser,

sei que o outro

me devolve o que sou.

O outro sinaliza o meu estado.

A senhora,

o outro

encontrou na minha cara,

no meu pescoço,

minhas mãos,

no meu andar,

Não estou imune.

A repetição fará

Com que meu eu 
Se acostume.

Essa minha resistência

É como turbulência

de avião;

faz parte do voo,

tem que acontecer.

É isso ou abrir mão

do que é viver.

(CARVALHO, 2018, p. 17-17)

O tratamento "senhora" causa-lhe um certo desconforto e o ser poético procura entender pois; "e fico ainda como quem aprende", mas, "quando vai embora, / o novo chamamento/ de senhora!" Nota-se o espanto do eu-poético diante da repetição da palavra "senhora", seguido pelo ponto de exclamação. A forma de tratamento "senhora" que segundo Faraco (2017), tem origem no latim e significa "mulher mais velha", porém entrou no português por meio do francês. Por outro lado, sabe-se que senhor(es)/senhora(s) se refere a tratamento respeitoso utilizados em cerimoniais e também podem ser seguidos de títulos acadêmicos, honoríficos, hierárquicos.

Culturalmente este pronome de tratamento destinado à mulher, no seu cotidiano, tem certa carga pejorativa, visto que para a lei brasileira, idoso é quem tem mais de sessenta anos. Contudo, como a comunidade científica vem demonstrando, por meio dos mecanismos de vida saudável, homens e mulheres estão ultrapassando as expectativas de vida e logram alcançar a maturidade com surpreendente vigor, lucidez mental, equilíbrio emocional e tudo que habilita a reconsideração e o remanejamento da faixa que considera como idosas, as pessoas longevas bem-sucedidas que ultrapassam os oitenta anos. Porém, no poema selecionado, o peso da palavra ressoa aos ouvidos do eu poético como um grito de espanto "SENHORA!", grafado com letras maiúsculas, para demonstrar o tamanho do seu inconformismo, porque

Os mitos e os clichês posto em circulação pelo pensamento burguês se aplicam em
mostrar o velho como um outro. [...] Levamos tão longe este ostracismo que chegamos
a voltá-lo contra nós mesmos; recusamo-nos a nos reconhecer como velho que
seremos: "de todas as realidades; [a velhice] é, talvez, aquela que conservamos por
mais tempo, ao longo da vida, uma noção puramente", observou, com propriedade,
Proust. (BEAUVOIR, 2018, p. 11-12).

O efeito estético ressoa com intensidade, tal como "turbulência de avião"; sabemos que vai passar, contudo, causa tremor interno. Desarranja. Desassossega. A incomodidade causada pelo tratamento "senhora" persiste e eu poético interpela-se: "Como souberam? /Quem contou para eles/a minha idade? Será que é um complô/ que armaram na cidade?”. As seguidas

\footnotetext{
${ }^{1}$ Substantivo feminino. Tratamento cortês, dispensado a uma mulher casada e, em geral, a qualquer mulher de certa condição social, com alguma idade ou idosa.
} 
interrogações revelam como é difícil reconhecer que se está envelhecendo, porque a velhice é sempre associada à perda das forças que governam o corpo e, consequentemente, se está mais próximo da decadência, isto em uma sociedade que prima pelo frescor, pela beleza e pela juventude, corrobora, em certa medida, para a desvalorização do acúmulo de experiências vividas e saberes a transferir para as futuras gerações. A velhice, nos dias atuais, não representa mais sinônimo de experiência, poder e sabedoria como nas antigas civilizações. Ante visionar essa "terrível" ameaça faz com que o eu lírico se desvaneça no estado de inconformidade com a sua evidenciada condição.

No atual modelo de organização social capitalista, no qual estimula-se fortemente o consumo em massa, quando a pessoa deixa de integrar o sistema de produção não gerando mais renda e, passa a integrar o grupo de pessoas idosas, perde-se também o respeito. Segundo Pachá (2018), na contemporaneidade, pressionados pela segregação, os mais velhos devem se recusar a envelhecer, adoecer e morrer, porque

Viver em uma sociedade que incensa a juventude e nega a doença, a infelicidade, a deterioração e até mesmo a morte não é exatamente a melhor maneira de assimilar a passagem do tempo e os impactos que ela produz. Não desejamos morrer jovens, naturalmente. No entanto, a maior longevidade possibilitada pela ciência nas últimas décadas tem introduzido conflitos complexos no dia a dia. (PACHÁ, 2018, p. 2).

Conflitos vivenciados pelo eu lírico a partir da revelação do outro pelo tratamento "Senhora", num momento corriqueiro de compras. No entanto, a ponderação o conduz para a aceitação, pois "No fundo do meu ser, / sei que o outro/ me devolve o que sou. O outro sinaliza o meu estado." O outro se revela para o eu lírico como espelho que lhe devolve a imagem daquilo que foi refletido. No poema "Retrato" de Cecília Meireles e em "A Busca da Resiliência" de Luciene Carvalho, a indagação da própria imagem leva à constatação de profundas mudanças perpetradas em suas pessoas e que sequer foram antevistas pelas poetas. Ou seja, a passagem da vida enquanto perda de faces, visto que o poema de Cecília Meireles, assim como o de Luciene Carvalho vertem -se para o espelho,

[...] quase que promovendo, como se vê, uma igualdade, uma equiparação entre os dois objetos, esses dois modos de se enxergar, de se auto perscrutar, visto que ambos são, por assim dizer, reflexivos. [...] malgrado enfoque o tempo transformador e inexorável, a mudança sem remissão, aponta, ao mesmo tempo, para o desmembramento, para a transfiguração, para o desdobramento de rostos. (FARRA, 2005, p. 353).

No poema "Retrato" o eu lírico constata que "Eu não tinha este rosto de hoje,/ Eu não tinha estas mãos sem força," do mesmo modo, o eu lírico Lucienico descobre que envelheceu e que o outro percebeu, pois foi o outro que "encontrou em minha cara, meu pescoço, minhas 
mãos, meu andar." Para atingir reconhecimento que o tempo passou e transformou o próprio corpo é causa de estranhamento; pois aquilo que somos é absorvido pelo outro, segundo Beauvoir, 2018, em um de seus relatos sobre a constatação da velhice, diz

\begin{abstract}
Aí está o que me surpreendia mais: o tempo era, por assim dizer, visível a olho nu. "O aspecto inteiramente novo de um ser com M. d'Argentcourt era para mim uma revelação surpreendente daquela realidade do milésimo que habitualmente parece abstrata para você.......] Percebi pela primeira vez, a partir das metamorfoses que haviam produzido em todas aquelas pessoas, o tempo que havia passado para elas, e o que me perturbou, pela revelação de que também ele também passara." [...] "Não víamos nosso próprio aspecto, nossas próprias idades, mas cada um, como num espelho diante de si, via a idade do outro." (BEAUVOIR, 2018, p. 304).
\end{abstract}

Na perspectiva da autora citada, o adolescente se dá conta de que atravessa um período de transição; as transformações do seu corpo são visíveis, por outro lado o idoso sente-se velho através dos outros, sem ter experimentado sérias mutações. A imagem que o espelho reflete não mostra o tempo, mas apenas a face do que restou no tempo.

Enquanto no poema "Retrato" de Cecilia Meireles o eu-poético se intensifica na procura por se reconhecer, buscando inutilmente uma face desaparecida no tempo, mostrando uma certa vulnerabilidade íntima. Enquanto que no poema "A Busca pela Resiliência" de Luciene Carvalho o eu poético reconhece que "Eu não estou imune"/ A repetição fará com que eu/ se acostume.", transitando, assim para uma nova fase da vida, porque, "faz parte do voo/ tem que acontecer./ É isso ou abrir mão do que é viver." Resiliente transcende o limite entre as fases da vida compreendendo que o tempo se apresenta inexoravelmente e viver é uma sequência.

O segundo poema da primeira parte de Dona (2018), intitulado “As invisíveis”, (p.19), conduz o eu-poético ao encontro de outras mulheres que também estão deixando a fase da maturidade em direção à velhice, ou seja, no momento de transição. A tomada de consciência do tempo conduz o eu-poemático à observação iniciando com o verbo "ter": "Tenho Olhado, / olhado muito as mulheres de cinquenta, /de quase cinquenta, /de cinquenta e poucos, /de cinquenta e muitos." O olhar intensificado pelo advérbio "muito" revela simultaneamente, certa conformidade e resistência por parte do eu poético que recém se descobriu integrante deste grupo de mulheres.

Assim, prossegue seu discurso poético, novamente com o verbo ter, pois: "Tenho colocado em pauta/ essas mulheres como assunto. / Vejo-as no ônibus... /atravessando ruas.../ comprando em lojas..." Essas mulheres estão por toda a parte. Ressalta-se que uso das reticências como recursos estilísticos que evidenciam que elas são muitas, estão por toda a parte. As evidências nos direcionam para os dados apontados pelo Jornal da USP, 2018, o número crescente de idosos no mundo. Segundo dados do Ministério da Saúde, o Brasil, em 2016, tinha 
a quinta maior população idosa do mundo, e, em 2030, o número de idosos ultrapassará o total de crianças entre zero e 14 anos.

Nos versos seguintes o eu-poético lança um olhar consternado sobre essas mulheres, pois a percepção da invisibilidade delas a conduz ao questionamento: "Estranhos o quanto elas são invisíveis/para o mundo, /para os olhares, /e me pergunto:/ O que elas sentem? / O que elas sentem? / Não são velhas/e já não são jovens;/ são uma espécie de canteiro/ entre uma e outra pista?" As indagações poéticas colocam essas mulheres de quase cinquenta, cinquenta e poucos e cinquenta e muitos no meio de uma pista e outra, visto que a sociedade segue em movimento nas pistas e as mulheres que carregam o peso de meio século estão paradas no "meio" do percurso. Já não despertam o interesse, a atenção para seus traços perfeitos e os olhares de desejo. O eu-poético transfigura-se em espelho dessas mulheres, pois as vê no meio do canteiro plantadas como árvores que estão ali todos os dias, mas a agitação e correria do mundo capitalista as tornam invisíveis.

Paira uma certa dúvida, o eu-poemático reflexivo diz "Talvez exista juventude nelas," porque o confronto com o espelho é penoso para a mulher. Ainda que exista juventude elas estão sobre o canteiro e o retornar é impossível. Inevitavelmente irá transpor o canteiro, visto que as poucas marcas de juventude se mesclam na dúvida de que "talvez a velha já pese em seus passos..." E, a recorrência estilística pelo recurso das reticências denuncia que este caminho não tem retorno. Então, o eu poético se localiza, se integra ao grupo destas mulheres de meia idade, assim: "Faço dessas fêmeas tema dos meus versos, / porque os meus passos vão andar com elas."

No poema "Páscoa" de Adélia Prado, a subjetividade poética que aborda a temática do envelhecer está dividida em três fases:

\footnotetext{
"Velhice /

é um modo de sentir frio que me assalta/

e uma certa acidez.

$[\ldots]$

Divido o dia em três partes:

a primeira pra olhar retratos.

A segunda pra olhar espelhos,

a última e maior delas, pra chorar.

$[\ldots]$

(PRADO, 1991, p.30)
}

A tristeza e aflição causadas, na mulher, pelo próprio surpreender-se com o processo de envelhecer, Adélia Prado poetiza o percurso da vida em três fases, sendo a primeira "pra olhar retratos". Ao contemplar-se no retrato, vê-se bela e esplendorosa. Representa a vida 
desabrochado com toda vitalidade e frescor da juventude. Instiga desejos, se admira e sabe o poder de sedução que possuía.

A segunda fase "pra olhar espelhos," e nesta fase a mulher tenta buscar vestígios da sua beleza que se desmancha no tempo. Na perspectiva de Aboim (2014), para as mulheres, o confronto com o espelho e com a imagem nele refletida assinala o primeiro anúncio do processo de envelhecimento. Nesta fase que o eu poético Luciênico se encontra no poema "As Invisíveis", pois são aquelas mulheres que estão no meio, pois são canteiros, não são velhas e já não são jovens.

A terceira e última fase é subjetivamente apresentada pelo eu - poético adeliano como a mais difícil, é a fase destinada "pra chorar". A fase da velhice, segundo Aboim (2014), é aquela em que

[...] a velhice enreda os que a ela chegam nas tramas de uma solidão indesejada que, em larga medida e para a maioria, contrasta com os anos produtivos do curso de vida e assim impõe novos desafios à pessoa idosa. Esse é, como tem sido largamente discutido, um dos problemas graves associados ao envelhecimento. (ABOIM, 2014, p. 223).

Na perspectiva da autora citada o adolescente se dá conta que atravessa um período de transição; as transformações do seu corpo são visíveis, por outro lado o idoso sente-se velho através dos outros, sem ter experimentado sérias mutações. A imagem que o espelho reflete não mostra o tempo, mas apenas a face do que restou no tempo.

\section{CONSIDERAÇões FinAIS}

A contemporaneidade expressa-se nos poemas de Luciene Carvalho, pois tratam de temáticas atuais. As poetas modernistas visualizavam o desapreço que a sociedade, de sua época, tinha pela mulher idosa.

Nos poemas "A busca da Resiliência" e "A invisíveis" da coletânea selecionada para este estudo, o eu- poético lança seu olhar para a mulher que chega aos cinquenta anos. Descobrir que viveu meio século causa certo desconforto para o sujeito poético, visto que sociedade impõe para as pessoas a condição de serem e estarem em contato permanente com o novo.

Para a mulher, esta cobrança ainda é maior causando-lhe angústia e até mesmo constrangimento. $\mathrm{O}$ discurso do capitalismo faz com que a mulher se sinta mal com o processo do envelhecimento, pois são cobradas a serem jovens eternamente. Situação esta que atormentou outras poetas que vivenciaram a dolorosa perda da juventude, e também apresentaram sua dor e tristeza em versos. No poema "Retrato" de Cecilia Meireles o eu poético fica consternado e afetado pela sua aparência envelhecida em contraste com a da sua 
juventude. A imagem espelhada no retrato causa-lhe indignação, pois vê uma mulher velha. Segundo Beauvoir (2018) em La Mise à mort, Aragon simbolizou a ignorância e a confusão que a crise de identificação gera, pois o herói não é mais capaz de se ver.

Também no poema de Adélia Prado "Páscoa" a mesma dor afeta o eu -poético que se sente desolado, pois reconhece que perdeu a sua originalidade " $E u$, que fui loura e lírica, /não estou pictural." E a perda da juventude conduz à súplica: "Peço a Deus, /em socorro da minha fraqueza,". A fraqueza transcendente do físico identificada pelo eu-poético infesta o íntimo, a alma, pois é trágico para o eu feminino não se ver no próprio retrato.

Florbela Espanca no poema "Pior Velhice", a dor transborda e o eu poético reconhece a perda da juventude na afirmativa "Sou velha e triste. INunca o alvorecer". A velhice entrelaça-se à tristeza profunda na certeza que a seus dias primaveris jamais retornarão.

No poema "A busca da Resiliência" o eu poético é surpreendido pelo chamamento de "Senhora". O desconforto inicial, a resistência é associada a uma turbulência de avião é acomodada, pois faz parte do voo. O eu- poético não lamenta e resiliente enfrenta, "É isso ou abrir mão/ doa que é viver".

Em "As invisíveis" o eu poético Luciênico observa as mulheres de cinquenta ou mais. O seu lirismo percebe que estas mulheres são com uma espécie de canteiro entre uma pista e outra, ou seja, não são completamente velhas, mas também não são jovens. São canteiros. Estão exatamente no meio, mas como em Florbela Espanca reconhece que não tem retorno. E por isso faz dessas fêmeas tema de seus versos, porque seus passos vão andar com elas.

Ao poetizar a difícil aceitação da velhice o eu-poético revela que ser velho no mundo contemporâneo implica não somente nas perdas de habilidades físicas, mas também enquanto sujeito social. E para as mulheres a velhice é praticamente a inexistência para o mundo, pois ao perder o frescor da juventude se tornam “As Invisíveis", visto que segundo Beauvoir, (2018), nem na literatura, nem na vida, encontrou qualquer mulher que considerasse sua velhice com complacência. Do mesmo modo, que nunca se fala em "bela velha". No máximo se dirá "uma encantadora anciã". Por outro lado, certos 'belos velhos' são admirados, porque os cabelos brancos e as rugas não contradizem o ideal viril.

Fica evidente o quanto os poemas analisados estão permeados pelas questões do viver e estão intrinsecamente relacionados aos conceitos pejorativos pré-estabelecidos ao envelhecer da mulher, na sociedade contemporânea.

O eu-poético Luciênico, descobre-se num momento de transição, não é jovem e nem velha. Porém, suas entre linhas poéticas explicitam uma preocupação com as mulheres que 
amadurecem na sociedade brasileira, visto que o período da "velhice" que as aguardam, não será enfrentado por todas, da mesma maneira. O eu-poético se coloca ao lado delas; "porque os meus passos vão andar com elas.". Neste sentido, considera-se que a leitura dos poemas de Luciene Carvalho proporcionou reflexões pertinentes sobre a vida, porque a poesia não somente encanta, mas também denuncia.

\section{REFERÊNCIAS}

ABOIM, Sofia. Narrativas do envelhecimento: Ser velho na sociedade contemporânea.

Tempo Social, São Paulo, v. 26, n. 1, p. 207-232, jan./julho, 2014. DOI: https://doi.org/10.1590/S0103-20702014000100013. Disponível em: https://www.scielo.br/pdf/ts/v26n1/13.pdf. Acesso em: 19 mar.2020.

ALMEIDA, Jane Soares de. Mulher e educação: a paixão pelo possível. São Paulo: Editora UNESP, 1998.

AGLIARDI, Delcio Antônio; BOHM, Verônica. A poética do envelhecer em Adélia Prado.

TEXTURA - Revista de Educação e Letras, Canoas, v. 18, n. 37, p. 150-161, maio/ago., 2016. Disponível em: http://www.periodicos.ulbra.br/index.php/txra/article/view/2064. Acesso em: 14 maio 2020.

ANTONIALLI, Fabio; VIEIRA, Kelly Carvalho; ANTONIALLI, Luiz Marcelo; REZENDE, Daniel Carvalho. "Senhora está no céu!" Estudo sobre o Uso do Pronome de Tratamento em Lojas de Vestuário Feminino. REMARK - Revista Brasileira de Marketing, São Paulo, v. 14, n. 2., p. 193-207, abril/junho. 2015. DOI: 10.5585/remark.v14i2.2820. Disponível em: http://www.revistabrasileiramarketing.org/ojs2.2.4/index.php/remark/article/viewFile/2820/22 70. Acessado em: 05 maio 2020.

BEAUVOIR, Simone. A Velhice. Trad. MARTINS, Marai Helena Franco. 2. ed. Rio de Janeiro: Nova Fronteira, 2018.

BOSI, Alfredo. O ser e o tempo da poesia. São Paulo: Cultrix, 1977.

CARVALHO, Luciene. Dona. 1.ed. Cuiabá: Carlini \& Caniato editorial, 2018.

DUARTE, Constância Lima; PAIVA, Kelen Benfenatti. A mulher de letras: nos rastros de uma história. Ipotesi, Juiz de Fora, v. 13, n. 2, p. 11-19, jul./dez. 2009. Disponível em: https://periodicos.ufff.br/index.php/ipotesi/article/view/19180. Acesso em: 01 abril 2020.

DURÃO, Fabio Akcelrud. Reflexões sobre a metodologia de pesquisa nos estudos literários.

DELTA: Documentação de Estudos em Lingüística Teórica e Aplicada, São Paulo, v. 31, no spe., p. 377-390, ago. 2015. DOI: https://doi.org/10.1590/0102-445014919759499939. Disponível em: https://www.scielo.br/pdf/delta/v31nspe/1678-460X-delta-31-spe-00377.pdf. Acesso em 17 mar 2020. 
ESPANCA, Florbela. Pior velhice. In: ESPANCA, Florbela. Sonetos. 9. ed. Rio de Janeiro: Bertrand Brasil, 1997.

FARACO, Carlos Alberto. O tratamento de você em português: uma abordagem histórica. LaborHistórico, Rio de Janeiro, v.3, n.2, p. 114-132, jul./dez. 2017. DOI: http://dx.doi.org/10.24206/lh.v3i2.17150. Disponível em: https://revistas.ufrj.br/index.php/lh/article/view/17150/10437. Acesso em: 23 fev. 2020.

FARRA, Maria Lúcia Dal. Cecília Meireles: imagens femininas. Cadernos Pagu, Campinas, s/v, n. 27, p. 333-371, jul./dez. 2006. pp.333-371. Disponível em:

https://www.scielo.br/pdf/cpa/n27/32147.pdf. Acessado em 02 maio 2020.

FERREIRA, Amanda Crispim. MIGLIOZZI, Luiz Carlos Ferreira de Melo. Literatura AfroFeminina Brasileira do Século XXI: Corpo, Voz, Poesia e Resistência. In: ABRALIC Experiência literárias textualidades contemporâneas, 15., 2016, Rio de Janeiro. Anais [...]. Rio de Janeiro: UERJ, 2016.

GIL. Antonio Carlos. Como elaborar projetos de pesquisas. 4. ed. São Paulo: Atlas S.A., 2002.

HAHNER, June Edith. Emancipação do Sexo Feminino: a luta pelos direitos da mulher no Brasil. 1850-1940. Florianópolis: Editora Mulheres EDUNISC, 2003.

IBGE. Número de idosos cresce $18 \%$ em 5 anos e ultrapassa 30 milhões em 2017. Atualizado em 01/10/2018. Disponível: https://agenciadenoticias.ibge.gov.br/agencianoticias/2012-agencia-de-noticias/noticias/20980-numero-de-idosos-cresce-18-em-5-anos-eultrapassa-30-milhoes-em-2017. Acesso em 01 out. 2019.

JORNAL DA USP. Em 2030, Brasil terá a quinta população mais idosa do mundo. 2018. Disponível em: https://jornal.usp.br/atualidades/em-2030-brasil-tera-a-quinta-populacaomais-idosa-do-mundo/. Acesso em: 05 maio 2020.

MACIEL, Nahima. Conceição Evaristo: A literatura está nas mãos de homens brancos. Correio Braziliense. 2018. Disponível em:

https://www.correiobraziliense.com.br/app/noticia/diversao-earte/2018/07/15/interna_diversao_arte,694873/entrevista-conceicao-evaristo.shtml. Acesso em: 20 out. 2019 .

MEIRELES, Cecília Meireles. C. Antologia Poética. Rio de Janeiro: Editora Nova Fronteira, 2001.

PACHÁ, Andréa. Velhos são os outros.1. ed. Rio de Janeiro: Intrínseca, 2018.

PAZ, Octavo. Signos em rotação. 3.ed. São Paulo: Perspectiva, 1996.

PAZ, Octavo. EI arco y la lira. 3 ed. México: Fondo de Cultura Económico, 2003.

PRADO, Adélia. Poesia reunida. São Paulo: ARX, 1991.

RAGO, Magareth, VENTURI, Gustavo; RECAMÁN. Marisol. A Mulher Brasileira nos Espaços Públicos e Privados. São Paulo: Editora Perseu Abramo, 2004. 
SERRA, Edilson Floriano Souza. As múltiplas faces do feminino na escritura de Luciene Carvalho. Revista Claraboia, Jacarezinho, v.7, p. 35-44, jan./jun., 2017.Disponível em: http://seer.uenp.edu.br/index.php/claraboia/article/view/950/pdf. Acessado em: 20 out.2019.

VALDEREZ, Maurilia. O que pode a poesia. In: CARVALHO, Luciene. Dona. 1. ed. Cuiabá: Carlini \& Caniato editorial, 2018.

Recebido em: 18 de maio de 2020.

Aprovado em: 15 de julho de 2020. 